\title{
A new approach to calibration of the AWBM for use on ungauged catchments
}

\author{
Walter Boughton \\ Honorary Professor, Griffith University, \\ 11 Preston Place, Brookfield, Queensland 4069, Australia
}

\begin{abstract}
A new approach to calibration of the AWBM daily rainfall-runoff model was tested by transposing calibrated parameter values among 18 catchments in coastal Queensland, Australia. The calibration procedure adjusts input rainfall and evaporation by linear scaling with constraints on the calibrated value of average surface storage capacity to maximize the coefficients of efficiency based on monthly totals of runoff. The calibrated parameter values on each catchment were able to estimate runoff on each of the other 17 catchments with an average error of only $5.5 \%$. Some $94 \%$ of the $306(18 \times 17)$ estimates of runoff were within $15 \%$ of actual runoff. Some $71 \%$ of the coefficients of efficiency from the tests of transposing parameter values were $\geq 0.8$. A second stage of the study was to average the 18 sets of calibrated parameter values to a single set that estimated runoff from the 18 catchments with an average error of only $5.3 \%$ and a maximum error of $15.8 \%$. The new method of calibrating the AWBM offers potential for estimating runoff from ungauged catchments with small errors.
\end{abstract}

\section{INTRODUCTION}

Computer modelling of the water balance of catchments began about 1960 with the Stanford Watershed model. Since then, more than 100 water balance models have been described in the literature, and new models are still appearing. Soon after the first models appeared, attempts were made to use them for estimating runoff on ungauged catchments without much success. Where streamflow data are available for calibrating model parameters, the models work very well, but 40 years of effort by many researchers in many countries has not produced much success in modelling runoff on ungauged catchments. The recent Prediction in Ungauged Basins (PUB) and the Model Parameter Estimation Experiment (MOPEX) international programs have concentrated multi-national effort on the problem. See:

http://cee.uiuc.edu/research/pub $\quad$ (PUB)

http://www.nws.noaa.gov/oh/mopex $\quad$ (MOPEX)

In a recent publication of the MOPEX program, Merz et al (2006) reviewed the methods of using calibrations of rainfall-runoff models on gauged catchments for estimating runoff on ungauged catchments. The two main approaches are either to transpose values of model parameters from nearby catchments, or to derive relationships between model parameters and catchment attributes, which allows for use of calibrations from further away. The latter approach was the most common in the studies reviewed by Merz et al. They reported "All of the studies examined here reported relatively low correlations between model parameters and catchment attributes." 
Recently, Boughton (in review 2008) made a study of transposing sets of parameter values that were calibrated on one catchment and used to estimate runoff on other nearby catchments. Groups of three catchments in each of four states of Australia (Queensland, New South Wales, Victoria and Tasmania) were calibrated with the AWBM daily rainfall-runoff model and used to estimate runoff from the other catchments in the group. The estimated runoff varied from actual runoff by $\leq 10 \%$ in $50 \%$ of the tests and by $\leq 20 \%$ in $92 \%$ of the tests. The results suggested that transposing calibrated sets of parameter values offered potential for estimating runoff on ungauged catchments.

Those results prompted the present study to combine the scaling of rainfall and evaporation input data that had been shown to be effective in improving results where data were of poor quality with transposing sets of parameter values among catchments. A new method of calibrating the AWBM is tested, incorporating the method of scaling the input data described in Boughton (2006) with a new approach to avoiding extreme values of the main runoff generating parameter.

\section{DATA}

The 18 sets of rainfall and runoff data used in this study were originally part of a much larger collation of 331 data sets that were prepared for a runoff estimation project for the Australian National Land and Water Resources Audit (Peel et al 2001, Jeffrey et al 2001, Chiew et al 2002). The catchments are located in the more populated and important agricultural regions of Australia. Boughton and Chiew $(2003,2007)$ selected the better quality data and calibrated the AWBM on 213 sets for a study directed towards ungauged catchments. Subsequently, Boughton (2006) made a study of calibration of the AWBM with poor quality data, using 68 of the data sets that were omitted from the studies by Boughton and Chiew. Recently, Boughton (in review 2008) used some of the better quality data sets to explore the transposition of parameter values calibrated on one catchment for estimating runoff on another catchment as a means of estimating runoff on ungauged catchments. So the data sets have been well studied in several projects over several years. The 18 data sets in the present study are all from coastal Queensland, and their locations are shown in Figure 1. The distance from the most northern to the most southern is about $1500 \mathrm{~km}$.

The daily rainfall data are taken from the Queensland Department of Natural Resources \& Mining $0.05^{\circ}$ x $0.05^{\circ}$ (about $5 \mathrm{~km}$ x $5 \mathrm{~km}$ ) interpolated gridded rainfall data based on over 6000 rainfall stations in Australia (see www.dnr.qld.gov.au/silo ). The evaporation data are mean monthly areal PET values obtained from the evapotranspiration maps produced jointly by the Cooperative Research Centre for Catchment Hydrology and the Australian Bureau of Meteorology. The streamflow data are from the records of the Queensland Department of Natural Resources \& Mining. 


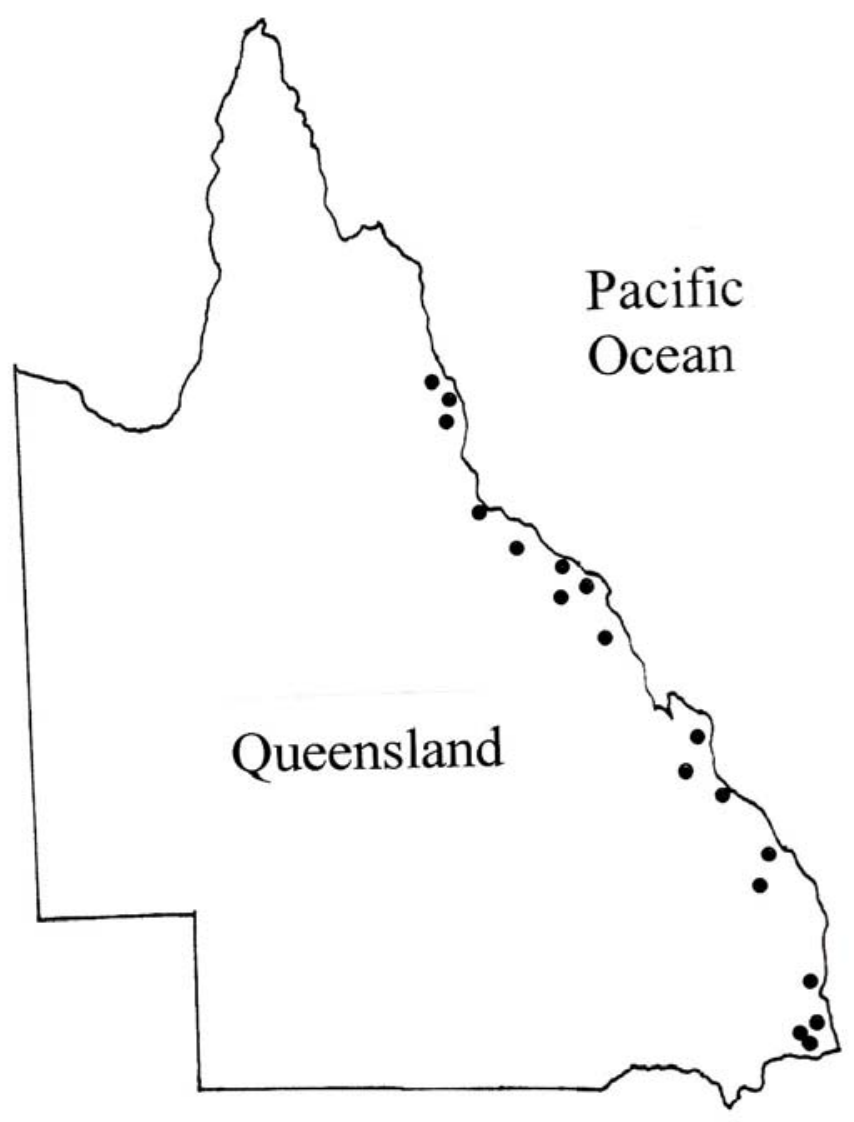

Figure 1 Locations of 18 catchments

Characteristics of the 18 catchments used in the present study are shown in Table 1.

\section{THE AWBM MODEL}

\section{Structure of the AWBM}

The daily rainfall-runoff model used in this study is the AWBM (Boughton 2004). The model calculates runoff as saturation excess from three surface stores of different capacities. This allows for partial area runoff at different times from different parts of the catchment during a storm. The structure of the model is shown in Figure 2. 


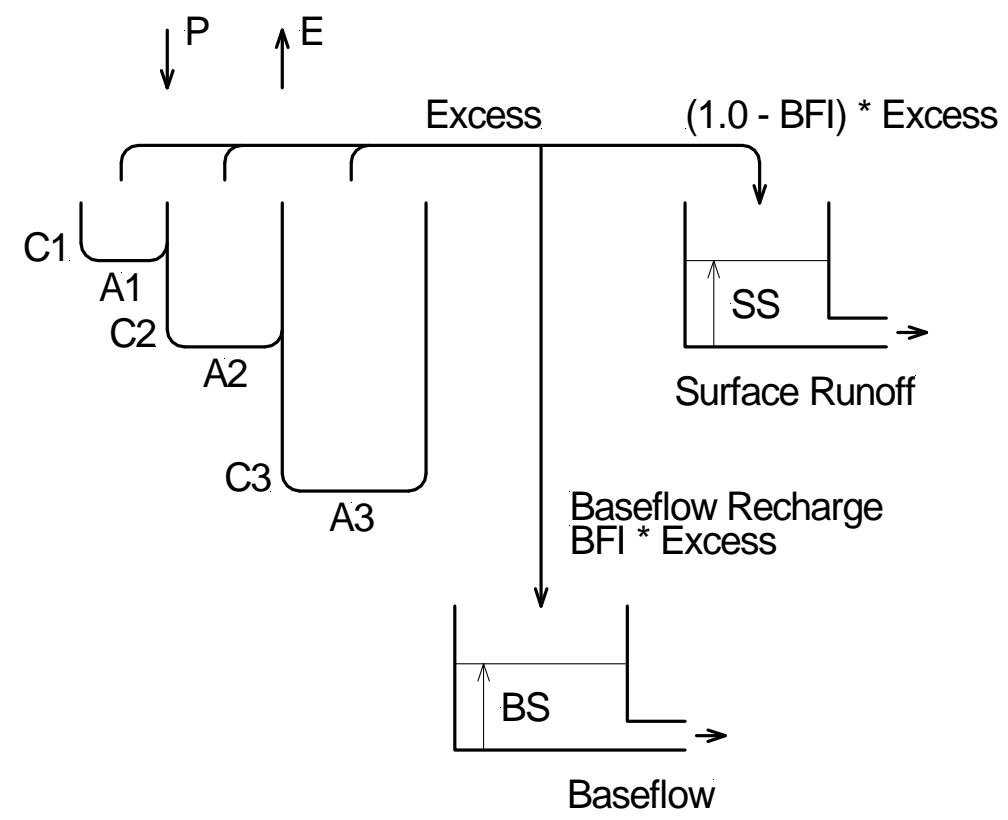

Figure 2 Structure of the AWBM rainfall-runoff model

There are three surface storage capacities $\mathrm{C} 1, \mathrm{C} 2$ and $\mathrm{C} 3$ that occupy partial areas of the catchment A1, A2 and A3 respectively. The average surface storage capacity is the sum of the three products of capacity and partial area, i.e. C1.A1 + C2.A2 + C3.A3. The average surface storage capacity is the single parameter determining the amount of runoff. In the daily water balance calculations, the daily rainfall is added to each of the three surface stores, and potential evapotranspiration is subtracted while water remains in the store. When the amount of water in any store exceeds the capacity of that store, the excess becomes runoff and the amount in store is reset to the capacity.

The runoff generated as excess from the surface stores is divided into surface runoff and baseflow recharge by the baseflow index (BFI). The discharge from baseflow storage each day is governed by the baseflow recession constant $\left(\mathrm{K}_{\mathrm{b}}\right)$ and calculated as $\left(1.0-\mathrm{K}_{\mathrm{b}}\right)$ times the amount in baseflow store (BS). The two baseflow recharge and discharge parameters affect the timing of runoff but not the amount of runoff.

\section{Calibration of the AWBM}

The AWBM was developed from an analysis of how the model structure would produce specific types of rainfall-runoff relationships (Boughton 2004). This made it possible to develop calibration procedures based on model structure rather than using trial and error testing of different sets of parameters.

The two earliest papers describing the methods of directly evaluating the surface storage capacities and their partial areas (Boughton 1987, 1990) preceded the publication of papers describing the model (Boughton 1993a, 1993b). The 1987 paper described the evaluation of capacities and partial areas with a graphical procedure that relies on selecting runoff events with none or very little antecedent moisture at the end of long dry periods. This was converted to an arithmetic procedure in Boughton (1990). Both of these methods dealt only with surface runoff. 
Immediately after publication of the first description of the model (Boughton 1993a), the problems of dealing with baseflow instead of only surface runoff prompted the development of a multiple linear regression method (Boughton 1993b, 2004). This dealt with monthly totals of flow, including baseflow as well as surface runoff. This was the main method of calibration in use for most of the next decade.

At the beginning of 2002, a self-calibrating version of the model was released for public use. By applying the multiple linear regression method to a number of high quality data sets, i.e. with very high correlations between actual and modeled runoff, it was found that the average surface storage capacity was far more important for calibration than the individual values of capacities and partial areas. An average pattern of capacities and areas was found that could be used for calibration without significant loss of accuracy in reproducing runoff (Boughton 2004). The automatic calibration procedure avoided subjective manual input and allowed for calibration of a large number of data sets for study of ungauged catchments.

In 2006, the automatic calibration method was extended to allow for scaling of input rainfall and evaporation data in a study of poor quality data (Boughton 2006). When input data are scaled, every daily data (e.g. daily rainfall) is multiplied by the same factor - see Table 3 for the factors used in the present study. This showed how scaling of input data could improve modelling on many poor quality data sets, and also showed that the calibrated parameter values of the model could be substantially changed by small changes in input data. That study showed that 68 out of 99 poor quality data sets could be significantly improved by scaling of rainfall and evaporation data.

The present study extends that latter work by showing that substantial improvements in modelling can be obtained by imposing a constraint on the calibration of the average surface storage capacity. This extension of the earlier calibration method has resulted in an approach to modelling runoff on ungauged catchments that is the main result reported in this paper.

\section{Method used in the present study}

The method of scaling rainfall and evaporation input data used in Boughton (2006) was modified to constrain the variation in average surface storage capacity. The earlier study showed that small variations in the scaling of rainfall produced big variations in the calibrated value of the average surface storage capacity that is the main parameter in the model determining the amount of runoff. The results of calibrating the AWBM on several hundred catchments (Boughton and Chiew 2007) indicated that the surface storage capacities clustered about $150 \mathrm{~mm}$, although the calibrated values ranged from almost zero to a few thousand $\mathrm{mm}$.

The scaling of rainfall and evaporation data is in increments of $5 \%$ with a coefficient of efficiency based on monthly totals of runoff calculated at each combination of adjusted rainfall and evaporation. In the present study, a constraint factor on the average surface storage capacity was calculated as follows. If the calibrated average surface storage capacity (Ave) is greater than $150 \mathrm{~mm}$, then a ratio is calculated as $150 /$ Ave, otherwise the ratio is calculated as Ave/150. This makes the ratio $\leq 1.0$. The 
calculated coefficient of efficiency E (Nash and Sutcliffe 1970) is then reduced to ratio ${ }^{0.125} \mathrm{E}$ to favor those combinations of rainfall and evaporation that have an average capacity closer to $150 \mathrm{~mm}$. The search routine then selects the best value of ratio ${ }^{0.125} \mathrm{E}$.

This does not force the average surface storage capacity to a single value but eliminates very big variations from the average value. The exponent 0.125 is a weighting factor that determines the relative influence of $\mathrm{E}$ and the value of the average surface storage capacity. A smaller value of the exponent will give more weight to $\mathrm{E}$ while a larger value gives more weight to the value of the average surface storage capacity. There is no theoretical basis for the value of 0.125 but the Results section of the paper shows that it provides a good mix of high values of $\mathrm{E}$ with capacity values clustered around $150 \mathrm{~mm}$.

\section{RESULTS}

Each of the 18 catchments was calibrated using the method described above. The new calibration method produced significant improvements in the coefficients of efficiency and more consistency in the values of the average surface storage capacity with only minor adjustments in the rainfall and evaporation input data.

\section{Improvements in the coefficient of efficiency}

The most usual measure of goodness of fit for evaluating daily rainfall-runoff modelling is to calculate the coefficient of efficiency comparing monthly totals of actual and modeled runoff. Table 2 summarizes the coefficients obtained on the 18 catchments with and without adjustments of input data. The column headed "Old" contains the results of calibration without adjustment of input rainfall and evaporation data. The column headed "New" contains the results from the new calibration procedure that is described earlier in the paper.

There is a significant improvement in the coefficient on all 18 catchments. The improvement in the lowest value of the coefficients from 0.58 to 0.79 shows that the method of calibration is better than the earlier method of automatic calibration of the model without any adjustment of input data.

\section{Adjustments of rainfall and runoff}

Table 3 summarizes the adjustments of rainfall and evaporation on the 18 catchments during the automatic calibration procedure. The adjustments were made in steps of $5 \%$, and the values in the table show the number of adjustments that finished in each step for the best calibration.

The calibrated adjustments of rainfall were four increases of rainfall, four catchments with no change, and 10 reductions in rainfall. The overall average of change is $-8 \%$. The values in adjustment of evaporation are more definitely reductions. There are only three increases in evaporation, two catchments with no change, and 13 reductions, with an overall average adjustment of $-17 \%$. 
There are two main reasons for the noteworthy reductions in evaporation data. First, the data are average monthly values that are the same in each year of modelling. The second and more important reason is that the AWBM uses potential evaporation without reduction until each of the surface moisture stores is empty. The model makes no reduction in the evaporation rate as the stores dry out. An earlier study of adjusting input rainfall and evaporation data (Boughton, 2006) on 68 catchments showed a very similar trend towards reduction in evaporation data with a very similar average of $14 \%$.

\section{Average annual rainfall and runoff}

Figure 3 shows the actual values of average annual runoff from the 18 catchments compared with the adjusted average annual rainfalls after the adjustment of rainfall and evaporation in the calibration procedure. It is uncommon for such data to form a close relationship with a narrow spread of values. The calibration method has no component that directs results towards such a relationship. The pattern shown in Figure 3 is an emergent result from collating the results from the 18 calibrations.

A linear regression fitted through the data in Figure 3 gave $\mathrm{Q}=0.588 \mathrm{P}-353$, where $\mathrm{Q}$ is average annual runoff and $\mathrm{P}$ is average annual rainfall. The equation suggests that there is no runoff below $600 \mathrm{~mm} / \mathrm{yr}$ rainfall, but there is little data on catchments with $600 \mathrm{~mm} / \mathrm{yr}$ rainfall on the Queensland coast, so the lower limit of this relationship is of questionable value; however, the slope of the relationship that runoff increases by 0.588 for each unit increase in rainfall has some significance for estimation of runoff on ungauged catchments. It implies that an error of $1.0 \mathrm{~mm}$ in estimating areal rainfall will cause an error of only $0.588 \mathrm{~mm}$ in estimated runoff.

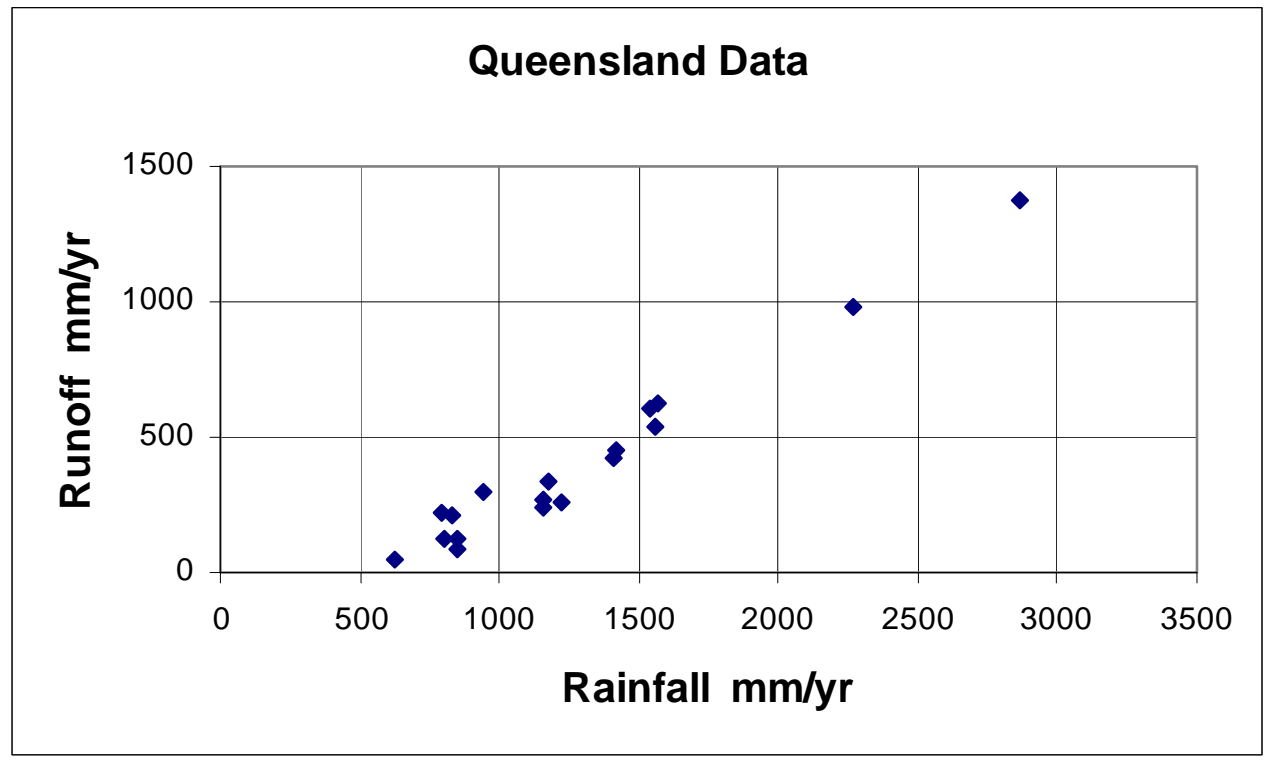

Figure 3 Average rainfall and runoff on the 18 Queensland catchments

\section{Average surface storage capacity}

The automatic calibration version of the AWBM uses a fixed pattern of the three surface storage capacities and their partial areas of the catchment. The single 
parameter that is optimized is the average surface storage capacity that is then disaggregated using the fixed pattern into the individual capacities and areas. The calibration procedure gives a negative weighting to any calibration that has an average capacity that is different from $150 \mathrm{~mm}$, so the calibrated values of average surface storage capacity cluster around that value.

The average of the calibrated values of average surface storage capacity is $149 \mathrm{~mm}$. Thirteen of the 18 calibrated values were within $5 \mathrm{~mm}$ of $150 \mathrm{~mm}, 16$ were within 10 $\mathrm{mm}$ and all were within $15 \mathrm{~mm}$, so the calibration procedure works to eliminate extreme variations in the main runoff generating parameter without enforcing a single value.

\section{Transposing parameter values to other catchments}

After calibrating all 18 data sets by the method described earlier, a major test was made by transposing each set of calibrated parameter values to each of the other 17 catchments in turn and comparing calculated and actual runoff. This gave $306(18 \mathrm{x}$ 17) tests to determine the accuracy of the calibrations for estimating runoff on ungauged catchments. The calibrated adjustments of rainfall and evaporation were used on each test catchment, and the calibrated parameter values of the AWBM from the other 17 catchments were used in turn to estimate runoff.

The results of the transposition of parameter values are impressive. Some $94 \%$ of the estimated values of runoff were within $15 \%$ of actual runoff, and the maximum error of estimate was $18 \%$. Some $59 \%$ of the estimates were within $5 \%$ of actual runoff. The mean error of estimate was 5.5\%. Figure 4 gives a visual comparison of estimated and actual runoff that shows how accurate the estimates are. Each of what appears as 18 dots is a group of 17 results.

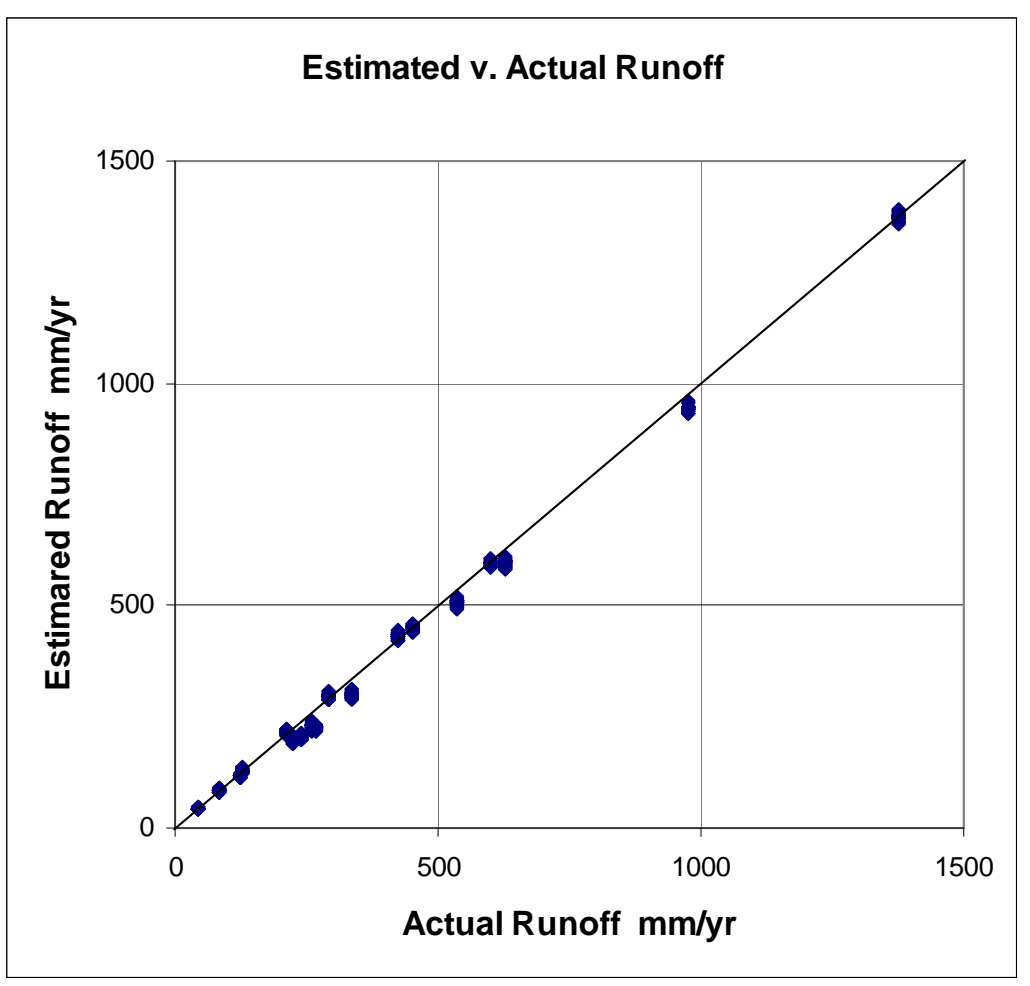


Figure 4 Comparison of estimated and actual runoff from 306 transpositions of parameter values

There were differences among the catchments. Gauging station 111007 had the biggest rainfall $(2862 \mathrm{~mm} / \mathrm{yr})$ and runoff $(1376 \mathrm{~mm} / \mathrm{yr})$ and had the smallest mean error of estimate of runoff $(0.5 \%)$. The largest mean error of $15.8 \%$ was on station 145018 with mean rainfall of $1537 \mathrm{~mm} / \mathrm{yr}$ and mean runoff of $267 \mathrm{~mm} / \mathrm{yr}$. There is a slight trend towards larger percentage error with smaller means of rainfall and runoff but not sufficient to show any significant relationship.

These results are based on total runoff over the period of available data. The next finer measure is the monthly pattern of runoff. The measure of accuracy at this time interval is the coefficient of efficiency based on monthly totals of runoff. The coefficient of efficiency was calculated for each of the 306 tests of transposing parameter values. Some $34 \%$ of the coefficients were $\geq 0.9$ and some $71 \%$ were $\geq 0.8$. The mean value was 0.82 . Some $7 \%$ were lower than 0.5 and the lowest was 0.17 .

It is premature to consider how accurate daily values of runoff on ungauged catchments can be estimated but some comment is warranted. The two baseflow parameters in the AWBM, the baseflow index and the daily baseflow recession constant, are the parameters that have most effect on the daily pattern of runoff after the surface storage capacity determines the amount of runoff. Although a few studies in Australia have investigated the relationships of these parameters with measurable characteristics, none have produced any reliable methods for estimated values of these parameters on ungauged catchments. This is the limiting factor for considering the estimation of daily values of runoff on ungauged catchments.

\section{Average set of parameter values}

The results from transposing each of the parameter sets to each of the other catchments immediately suggested that an average set of parameter values, taken from the 18 calibrations, should also give similar results. An average set of the three parameters for the AWBM from the 18 calibrations was Ave $=150 \mathrm{~mm}$, BFI $=0.23$ and $\mathrm{K}_{\text {base }}=0.92$, where Ave $=$ the average surface storage capacity, BFI is the baseflow index and $\mathrm{K}_{\mathrm{b}}$ is the daily baseflow recession constant. This single set of parameter values was used with each of the adjusted rainfall and evaporation values on the 18 catchments to estimate runoff over the period of available data. Figure 5 shows a comparison of actual and estimated runoff for the 18 catchments. 


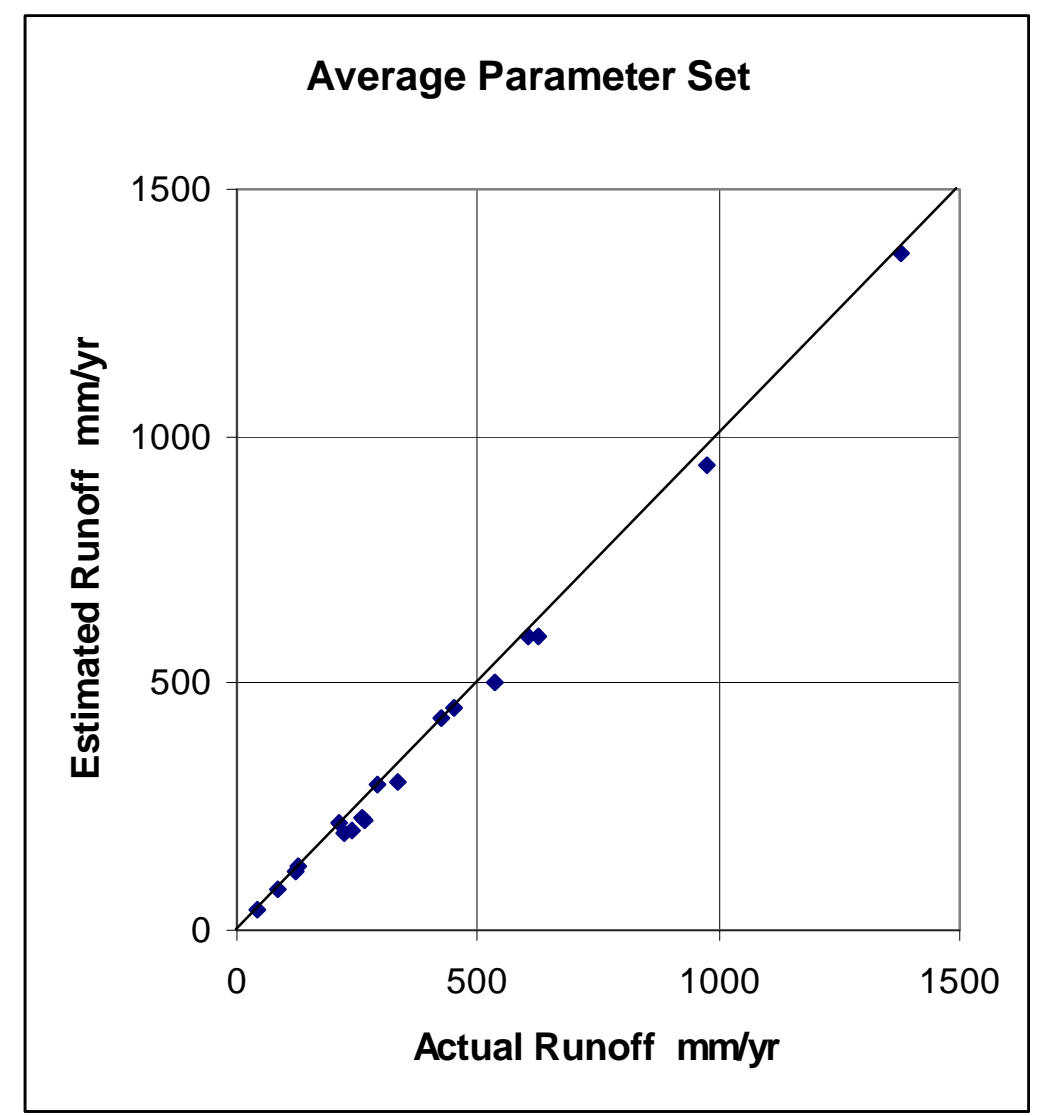

Figure 5 Comparison of actual and estimated runoff using the average set of parameter values.

The average error of estimation of runoff was $5.3 \%$ with a maximum value of $15.8 \%$.

\section{Catchment characteristics}

The original studies with these data for the National Land and Water Audit (Peel et al., 2001; Chiew et al., 2002) included estimates of six catchment characteristics. There were two measures of topography, two of vegetation, and two of soil characteristics. The six characteristics are:

- Median elevation of the catchment in metres

- Range of elevation - 90 percentile minus 10 percentile

- Leaf area index (LAI)

- Percent of woody vegetation

- Plant water holding capacity - mm (PAWHC)

- Soil transmissivity $-\mathrm{m}^{2} /$ day

Table 4 gives the values of the six characteristics from the original study. The 18 catchments have a wide range of values of the characteristics in addition to the wide ranges of rainfall and area; yet, a single set of parameter values produces estimates of runoff on all catchments with errors of only a few percent. 
Boughton and Chiew (2007) also tested these same catchment characteristics on 213 catchments from the original National Land and Water Audit study. They produced linear regressions relating mean annual runoff to mean annual rainfall and evaporation. They reported "Six catchment characteristics were tested in turn with the regression equations but none produced any improvement to the estimates of average annual runoff." The present study adds to the negative results relating catchment characteristics to runoff on ungauged catchments (see Conclusions $1^{\text {st }}$ paragraph).

\section{DISCUSSION}

The original direction of this study was towards transposition of calibrated parameter values from gauged to ungauged catchments as a means of estimating runoff on ungauged catchments. The unexpected result that each of the 18 calibrated parameter sets could be used on all of the other catchments with only small errors in the estimation of runoff suggested that an average of all of the calibrated parameter values would provide a single set of values for use on all of the catchments. This second part of the study has produced results that confound a great deal of past thinking on the estimation of runoff on ungauged catchments.

The 18 catchments in this study range in size of catchment from 78 to $1310 \mathrm{~km}^{2}$ with a range of mean annual runoff from 43.4 to $1376 \mathrm{~mm}$; yet, the mean annual runoff on all catchments can be accurately estimated from a single set of model parameter values with only minor adjustment of the input rainfall and evaporation. The mean error of estimating runoff with the single set of parameter values was only $5.3 \%$ and the maximum error was $15.8 \%$. Fourteen of the 18 coefficients of efficiency calculated from monthly totals of runoff were greater than 0.85 . Table 4 shows that there are significant variations in the catchment characteristics of the 18 catchments that are spread over $1500 \mathrm{~km}$ of the Queensland coast and are not a local and similar group.

The new method of calibration used in this study is not a recent idea but is the end product of development of calibration methods specific to the AWBM that have evolved over more than 20 years. The new addition to the calibration process of constraining the value of the average surface storage capacity to eliminate extreme calibrated values of capacity produced substantial and unexpected results that have opened a new direction towards the estimation of runoff on ungauged catchments.

The minor adjustments of rainfall and evaporation input data were not calibrated to the single set of parameter values that evolved from the study. Each adjustment of input data was made by calibrating only to the runoff on that catchment. The adjustments of rainfall and evaporation data were made in increments of 5\% that is relatively coarse compared with the small errors of estimating runoff. There is a need for more study of the adjustments of input data with finer increments. The adjustments of rainfall are small compared with suggested errors in the estimation of areal rainfall. Hall and Barclay (1975) reported that "Areal rainfall estimates based on point observations should only be regarded as an index of the true mean rainfall over a catchment and errors between 10 and 20 per cent can be regarded as normal. Where strong wind effects or mountainous catchments are being considered, errors up to 60 per cent can be experienced." 
The estimation of total runoff on all catchments is very good. The estimation of runoff at monthly time steps, measured by the coefficient of efficiency based on monthly totals, ranges from satisfactory to very good. The unresolved deficiency is the estimation of runoff at daily time steps. There is a need for methods of estimating the baseflow index and daily baseflow recession constant in order to be able to estimate the daily pattern of runoff on ungauged catchments. At present, there are no methods available with demonstrated capability for use on Australian catchments.

\section{CONCLUSIONS}

There is accumulating evidence that small errors in the estimation of areal rainfall and evaporation has much more significance in the calibration of parameters in rainfallrunoff models than catchment characteristics. This is borne out by the present study that shows substantial effects of small errors in input data but no effects due to catchment characteristics. There is an abundance of publications showing significant differences in runoff between forested and grassed catchments; yet these studies have almost all been on small catchments. It is uncertain why that established difference does not show up in studies on larger catchments; however, the variations now becoming apparent due to errors in estimating areal rainfall on large catchments could be responsible for masking small area effects. This is not yet established conclusively but the accumulating evidence is persuasive.

The AWBM does not calculate either snow pack/snowmelt or transmission loss in stream channels above the gauging station. Many of the northern hemisphere data sets that have been tested by the writer show evidence of snow pack/snow melt, and some modification of the model would be required for testing on those data. The writer is familiar with the major effects of transmission loss in arid areas such as southern Arizona (Boughton and Stone 1985). The common version of the AWBM does not incorporate such effects in such areas. It is unrealistic to expect that a single model will be adequate for these variations in catchment conditions, and some caution is required in extrapolating the results from this study to other catchments.

It is a cliché among rainfall-runoff modelers that any of the modern rainfall-runoff models give good results with good quality data, but none give good results with poor quality data. In other words, the quality of results in rainfall-runoff modelling depends more on the quality of the input data than on the quality of the model. Yet, very little attention has been given to how to overcome errors in, or improve the quality of, input data. The results presented here are due in no small part to the new calibration method of the AWBM that adjusts for the quality of input data. This method is the end product of some 20 years of research into calibration methods specific to the AWBM and cannot be simply applied to other rainfall-runoff models.

The main conclusion from the study is that more attention needs to be given to errors in input data and to calibration methods before rainfall-runoff modelling on ungauged catchments becomes a routine practicality.

\section{REFERENCES}

Boughton, W. C. (1987). "Evaluating partial areas of watershed runoff." Amer. Soc. Civ. Engs., Jour. Irrig. \& Drain., 113(3), 356-366. 
Boughton, W. C. (1990). "Systematic procedure for evaluating partial areas of watershed runoff." Amer. Soc. Civ. Engs., Jour. Irrig. \& Drain., 116(1), 83-98.

Boughton, W. C. (1993a). "A hydrograph-based model for estimating the water yield of ungauged catchments." In: Proceedings of the 1993 Hydrology \& Water Resources Conference, Institution of Engineers Australia, National Conference Publication no. 93/14, pp.317-324.

Boughton, W. C. (1993b). "Direct evaluation of parameters in a rainfall-runoff model." In: McAleer, M., Jakeman, A. (Eds), Proceedings of the International Congress on Modelling \& Simulation, vol.1. Modelling \& Simulation Society of Australia, pp.13-18.

Boughton, W. C. (1996). "Detecting data errors in rainfall-runoff data sets." Report 96/2, Cooperative Research Centre for Catchment Hydrology, Monash University, 23 pp.

Boughton, W. C. (2004). "The Australian Water Balance Model." Environmental Modelling and Software, 19, 943-956.

Boughton, W. (2006). "Calibrations of a daily rainfall-runoff model with poor quality data." Environmental Modelling and Software, 21, 1114-1128.

Boughton, W. (in review 2008). "Transposing parameter values for rainfall-runoff modelling on ungauged catchments." Submitted for publication.

Boughton, W. and Chiew, F. (2003). "Calibrations of the ABM for use on ungauged catchments." Technical Report 03/15, CRC for Catchment Hydrology, Monash University, $37 \mathrm{pp}$.

Boughton, W. and Chiew, F. (2007). "Estimating runoff in ungauged catchments from rainfall, PET and the AWBM model." Environmental Modelling \& Software, 22, 943 956.

Boughton, W. C. and Stone, J. J. (1985). "Variation of runoff with watershed area in a semi-arid location." Jour. of Arid Environments, 9, pp.13-25.

Chiew, F.H.S., Peel, M.C. and Western, A.W. (2002). "Application and testing of the simple rainfall-runoff model SIMHYD." In: Mathematical Models of Small Watershed Hydrology and Applications (Editors: V.P. Singh and D.K Frevert), Water Resources Publication, Littleton, Colorado, (ISBN 1-887201-35-1), pp. 335-367.

Hall, A. J. and Barclay, P. A. (1975). "Methods of determining areal rainfall from observed data." In: Chapman, T. G. and Dunin, F. X., "Prediction in Catchment Hydrology", Australian Academy of Science, Canberra, pp.47-57.

Jeffrey, S. J., Carter, J. O., Moodie, K. B. and Beswick, A. R. (2001). "Using spatial interpolation to construct a comprehensive archive of Australian climate data." Environmental Modelling \& Software, 16(4), pp.309-330. 
Merz, R., Blöschl, G. and Parajka, J. (2006). "Regionalization methods in rainfallrunoff modelling using large catchment samples." In: Andréassian, V., Hall, A., Chahinian, N. and Schaake, J. (Eds.) 'Large sample basin experiments for hydrological model parameterization: Results of the model parameter experiment MOPEX', IAHS Publ. 307, pp.117-125.

Nash, J.E. and Sutcliffe, J.V., 1970. River forecasting using conceptual models, 1. a discussion of principles. Jour. Hydrology, 10: 282-290.

Peel, M.C., Chiew, F.H.S., Western, A.W. and McMahon, T.A. (2001). "Extension of Unimpaired Monthly Streamflow Data and Regionalisation of Parameter Values to Estimate Streamflow in Ungauged Catchments." Report prepared for the National Land and Water Resources Audit, In http://audit.ea.gov.au/anra/water/docs/national/streamflow/streamflow.pdf 
Table 1 Details of catchments

\begin{tabular}{|l|l|r|c|c|c|}
\hline Station & Stream & Area & \multicolumn{3}{|c|}{ Mean Annual Values mm/yr } \\
\cline { 4 - 6 } Number & & km $^{2}$ & Rain & Evap $^{*}$ & Runoff \\
\hline 110003 & Barron R. & 220 & 1497 & 1762 & 628 \\
\hline 111007 & Mulgrave R. & 545 & 2862 & 1840 & 1376 \\
\hline 112003 & N. Johnstone R. & 173 & 1975 & 1814 & 976 \\
\hline 117002 & Black R. & 260 & 1110 & 1766 & 294 \\
\hline 119003 & Haughton R. & 260 & 875 & 1773 & 212 \\
\hline 120216 & Broken R. & 78 & 1712 & 1712 & 602 \\
\hline 121002 & Elliott R. & 270 & 938 & 1819 & 223 \\
\hline 122003 & Proserpine R. & 270 & 1180 & 1785 & 334 \\
\hline 125002 & Pioneer R. & 740 & 1417 & 1734 & 453 \\
\hline 129001 & Waterpark Ck. & 245 & 1484 & 1763 & 538 \\
\hline 130319 & Bell Ck. & 300 & 698 & 1591 & 43 \\
\hline 132001 & Calliope R. & 1310 & 851 & 1637 & 124 \\
\hline 135002 & Kolan R. & 545 & 945 & 1575 & 129 \\
\hline 136202 & Barambah Ck. & 640 & 896 & 1546 & 85 \\
\hline 142001 & Caboolture R. & 98 & 1485 & 1563 & 426 \\
\hline 145011 & Teviot Brook & 82 & 1106 & 1357 & 239 \\
\hline 145018 & Burnett Ck. & 81 & 1537 & 1360 & 267 \\
\hline 145102 & Albert R. & 545 & 1359 & 1395 & 260 \\
\hline
\end{tabular}

${ }^{*}$ Potential evapotranspiration 
Table 2 Summary of coefficients of efficiency

\begin{tabular}{|l|c|c|}
\hline \multirow{2}{*}{ Range of E } & \multicolumn{2}{|c|}{ Number in Range } \\
\cline { 2 - 3 } & Old & New \\
\hline $0.95-1.00$ & & 2 \\
\hline $0.90-0.95$ & 5 & 9 \\
\hline $0.85-0.90$ & 9 & 5 \\
\hline $0.80-0.85$ & 1 & 1 \\
\hline $0.75-0.80$ & 2 & 1 \\
\hline $0.55-0.60$ & 1 & \\
\hline Ave E & 0.86 & 0.91 \\
\hline Min E & 0.58 & 0.79 \\
\hline
\end{tabular}


Table 3 Number in each value of adjustment of rainfall and evaporation

\begin{tabular}{|c|c|c|}
\hline Adjustment & \multicolumn{2}{|c|}{ Number } \\
\cline { 2 - 3 } Factor & Rain & Evap \\
\hline 1.15 & 1 & \\
\hline 1.10 & & 2 \\
\hline 1.05 & 3 & 1 \\
\hline 1.00 & 4 & 2 \\
\hline 0.95 & 3 & 1 \\
\hline 0.90 & 3 & 1 \\
\hline 0.85 & 3 & 1 \\
\hline 0.80 & & 6 \\
\hline 0.75 & 1 & \\
\hline 0.70 & & 2 \\
\hline 0.65 & & 2 \\
\hline Ave & 0.92 & 0.83 \\
\hline
\end{tabular}


Table 4 Characteristics of the catchments

\begin{tabular}{|c|c|c|c|c|c|c|}
\hline \multirow{3}{*}{$\begin{array}{l}\text { Station } \\
\text { No. }\end{array}$} & \multicolumn{6}{|c|}{ Catchment Characteristics } \\
\hline & \multicolumn{2}{|c|}{ Elevation } & \multirow[b]{2}{*}{ LAI } & \multirow[b]{2}{*}{$\begin{array}{l}\% \\
\text { Woody }\end{array}$} & \multirow[b]{2}{*}{ PAWHC } & \multirow[b]{2}{*}{ transmissivity } \\
\hline & median & $\begin{array}{l}90 \%- \\
10 \% \\
\end{array}$ & & & & \\
\hline 110003 & 764 & 256 & 2.7 & 45 & 190 & 1604170 \\
\hline 111007 & 358 & 634 & 3.8 & 91 & 197 & 3671459 \\
\hline 112003 & 724 & 107 & 2.8 & 18 & 222 & 830294 \\
\hline 117002 & 90 & 364 & 1.8 & 84 & 89 & 1079410 \\
\hline 119003 & 129 & 361 & 1.2 & 65 & 86 & 3910200 \\
\hline 120216 & 757 & 204 & 3.6 & 97 & 169 & 1505145 \\
\hline 121002 & 85 & 222 & 1.3 & 72 & 82 & 648888 \\
\hline 122003 & 121 & 234 & 1.7 & 71 & 86 & 370275 \\
\hline 125002 & 254 & 501 & 2.7 & 96 & 146 & 2631984 \\
\hline 129001 & 48 & 83 & 2.5 & 93 & 107 & 2058394 \\
\hline 130319 & 335 & 221 & 1.8 & 68 & 64 & 368154 \\
\hline 132001 & 90 & 189 & 1.6 & 36 & 76 & 816088 \\
\hline 135002 & 251 & 266 & 2.5 & 86 & 72 & 279564 \\
\hline 136202 & 430 & 181 & 2.3 & 47 & 69 & 398180 \\
\hline 142001 & 200 & 362 & 2.7 & 52 & 143 & 1288371 \\
\hline 145011 & 346 & 505 & 3.6 & 64 & 103 & 474745 \\
\hline 145018 & 481 & 398 & 4.3 & 81 & 119 & 735300 \\
\hline 145102 & 169 & 493 & 2.9 & 59 & 144 & 1833510 \\
\hline
\end{tabular}

Notes:

Median

90\%-10\%

LAI

$\%$ Woody

PAWHC

Transmissivity

median elevation of catchment in metres range of elevation 90 minus 10 percentiles leaf area index percent of woody vegetation plant water holding capacity - $\mathrm{mm}$ soil transmissivity $-\mathrm{m}^{2} /$ day 